\title{
Responsabilidad de los administradores en la etapa preconcursal: situaciones de pérdidas patrimoniales ${ }^{1}$
}

\section{Director's Fiduciary Duties Before Insolvency: Events Of Equity Loss}

\section{Felipe Suescún de RoA ${ }^{2}$}

\section{RESUMEN}

Los administradores deben actuar protegiendo los intereses de los accionistas y de la sociedad en general. Durante el periodo preconcursal, más específicamente, cuando la sociedad se enfrenta a situaciones de pérdidas patrimoniales, los administradores deben abstenerse de iniciar nuevas operaciones sociales $y$, adicionalmente, deberán convocar a la asamblea general. De no cumplirse con tales deberes, los administradores serán solidariamente responsables de las deudas sociales posteriores a que se presente la situación de pérdidas patrimoniales.

1 Fecha de recepción: 21 de julio de 2015. Fecha de aceptación: 14 de diciembre de 2015. Para citar el artículo: Suescún, F. "Responsabilidad de los administradores en la etapa preconcursal: situaciones de pérdidas patrimoniales". Revist@E-Mercatoria, vol. 14, No2 julio-diciembre, 2015. DOI: https://doi.org/10.18601/16923960.v14n2.02

2 Socio en Suescún Abogados. Profesor de Cátedra de Obligaciones y Responsabilidad Civil en la Universidad de los Andes. Abogado de la Universidad de los Andes con Especialización en Derecho Comercial de la misma universidad. Maestría en Derecho (LL.M.) de Georgetown University Law Center. Fue asociado extranjero en el Grupo de Arbitraje Internacional de Freshfields Bruckhaus Deringer LLP en Washington D.C. Ha publicado diversos artículos, tanto en inglés como en español, en publicaciones nacionales e internacionales en aspectos relativos a arbitraje nacional e internacional, derecho comercial, corporativo, obligaciones, responsabilidad civil, contratos y derecho de los negocios en general. Contacto: felipesuescun@yahoo.com. 
Palabras clave: responsabilidad de los administradores, deberes fiduciarios, administradores, sociedades, derecho societario, accionistas, asamblea general, deber de diligencia, insolvencia, concurso, etapa preconcursal.

\begin{abstract}
Directors owe fiduciary duties to the company and its shareholders. Before insolvency, more specifically, when corporations are facing events of equity loss, directors should refrain from initiating new transactions and should call for a shareholders meeting. By not doing so, directors would be jointly and severally liable for corporate debts after the equity loss took place.
\end{abstract}

Key words: fiduciary duties, directors, corporations, corporate law, shareholders, shareholders meeting, duty of care, insolvency.

\title{
1. INTRODUCCIÓN
}

Tanto el artículo 457 del Código de Comercio como el artículo 34 de la Ley 1258 de 2008 establecen causales especiales de disolución de las sociedades anónimas y de las sociedades por acciones simplificadas (SAS), respectivamente. Nos enfocaremos, en este artículo, en la causal consagrada en el ordinal 2 del artículo 457 del Código de Comercio, la cual fue reproducida en el ordinal 7 del artículo 34 de la Ley 1258 de 2008, teniendo en cuenta que esta causal de disolución, además de ser la más frecuente, envuelve para los administradores el cumplimiento de ciertos deberes cuando la sociedad se encuentra en una situación de pérdidas patrimoniales lo que, de suyo, puede implicar que la misma se encuentre inmersa en una grave situación de crisis económica. ${ }^{3}$

Los citados ordinales establecen como causal de disolución de las sociedades anónimas y de las sociedades por acciones simplificadas, la siguiente: cuando ocurran pérdidas que reduzcan el patrimonio neto por debajo del cincuenta por ciento del capital suscrito. Bajo este supuesto, las pérdidas implican o bien que se hayan consumido los activos o se hayan aumentado los pasivos a tal punto que el patrimonio neto de la sociedad se vea reducido a la mitad del capital suscrito. ${ }^{4}$

3 "La situación de pérdidas graves, que es la causal de disolución más frecuente, puede estar vinculada, a pesar de que no necesariamente, con la situación de insolvencia de la sociedad, ya sea actual o inminente". Judith Morales Barceló, La responsabilidad de los administradores mercantiles en situación de pérdidas y de insolvencia (Valencia: Tirant lo Blanch, 2013), p. 319

4 Adolfo Sequeira Martin, La relación entre concurso y la situación de pérdidas patrimoniales graves como causa disolutoria en la sociedad anónima, en La Ley, núm. 6610, de 15 de diciembre de 2006, pp. 1646 y 1647. 
Es preciso puntualizar que dicha causal de disolución también es aplicable a la sociedad de responsabilidad limitada (artículos 370 y 372 del Código de Comercio), a las sociedades en comandita por acciones (artículo 352 del mismo estatuto) y a las sociedades en comandita simple (artículo 342$)_{i}^{5}$ así las cosas, dicha sanción no es aplicable a las sociedades colectivas.

Sin embargo, se debe aclarar que si bien el artículo 370 ibídem establece que "cuando ocurran pérdidas que reduzcan el capital por debajo del cincuenta por ciento" habrá una causal de disolución de las sociedades de responsabilidad limitada, se ha entendido que dicha causal, al igual que en las sociedades anónimas y en las sociedades por acciones simplificadas, se configura cuando las pérdidas disminuyan el patrimonio neto por debajo del cincuenta por ciento del capital. ${ }^{6}$

Para determinar la ocurrencia de la mencionada causal de disolución por pérdidas, se deben tener en cuenta dos aspectos, vale decir, el capital y el patrimonio neto. Respecto del primero, cabe precisar que se trata del capital suscrito y no sólo el pagado. ${ }^{7}$ En cuanto al patrimonio neto, el artículo 37 del Decreto 2649 de 1993 lo define como "el valor residual de los activos del ente económico, después de deducir todos sus pasivos".

Para la doctrina, la finalidad de establecer la obligatoriedad de la disolución de la sociedad cuando se vea inmersa en la causal que se viene tratando, es garantizar un equilibrio entre el patrimonio y el capital de la sociedad y que exista una correlación entre los datos publicados en el registro mercantil y el patrimonio realmente existente.

Dicha causal de disolución cumple una función preventiva, pues busca, principalmente, proteger a los acreedores de la sociedad por el riesgo que pueden afrontar, dada la situación en que se encuentra la sociedad y el régimen de responsabilidad limitada de la misma frente a sus acreedores. ${ }^{8}$ De esta forma, se evita que muchas sociedades que deberían estar disueltas permanezcan en el tráfico mercantil, generando inseguridad a los socios y a los acreedores, quienes pueden ver afectada su prenda general.

5 El artículo 342 del Código de Comercio establece que "La sociedad en comandita simple se disolverá, también, por pérdida que reduzca su capital a la tercera parte o menos." (subrayado fuera de texto)

6 Superintendencia de Sociedades de Colombia, Oficio 220-4880 de septiembre 25 de 2002.

7 En la legislación española, a diferencia de la colombiana, no se menciona expresamente el capital suscrito sino el "capital social." A este respecto, la doctrina ha señalado que se trata del capital suscrito. En este sentido véase, por ejemplo, Jesús Quijano González, Responsabilidad de los administradores por no disolución de la sociedad, en Rds, núm. 5/1995, p.270.

8 "Estos riesgos son la posible falta de información que tengan los acreedores, la falta de pago o aseguramiento de los créditos y la exposición de los riesgos a los que se ve sometido el patrimonio de la sociedad por la continuación de la actividad". Fernando Marín de la Bárcena Garcimartín, Responsabilidad por deudas y derecho de daños, en RdS, núm. 31/2008, pp. 403 y 407. 
El presente artículo de investigación y reflexión busca identificar cuáles son los deberes de los administradores en la etapa preconcursal, particularmente, cuando las sociedades se encuentran en situación de pérdidas patrimoniales. Para tal efecto, en primer lugar, se explicaran las diferencias en aquellos casos en que las empresas afrontan pérdidas graves y cuando están en insolvencia. Se precisan, además, los deberes de los administradores en situación de pérdidas graves, esto es, el de abstenerse de iniciar nuevas operaciones sociales y el de convocar a la asamblea general. Finalmente, se hará referencia a las consecuencias a que se pueden ver enfrentados los administradores, de no cumplir los mencionados deberes.

\section{DIFERENCIA ENTRE LA SITUACIÓN DE PÉRDIDAS GRAVES Y LA DE INSOLVENCIA}

La situación de pérdidas patrimoniales, como ya ha sido mencionado, es indicadora, en la mayoría de los casos, de una situación de grave crisis económica. Es por ello que la doctrina le ha otorgado a dicha causal de disolución una función preconcursal o preventiva, toda vez que se busca evitar que la sociedad llegue a una situación de insolvencia, con el consiguiente daño a los acreedores.

Para evitar que una sociedad llegue al estado de insolvencia, se establece un mecanismo preventivo, vale decir: en una situación de pérdidas de más de la mitad del capital social (y no necesariamente de insolvencia) la sociedad ha de disolverse y liquidarse de forma voluntaria o, alternativamente, se debe eliminar ese desequilibrio patrimonial, si los administradores no realizan los actos necesarios para que los pertinentes acuerdos sociales se lleguen a adoptar y a ejecutar, responderán por las nuevas obligaciones sociales. ${ }^{9}$

Cuando el patrimonio neto se reduce por debajo del cincuenta por ciento del capital suscrito, aquél sigue siendo positivo, de manera que la causal de disolución busca que esa situación no se agrave hasta llegar a un patrimonio neto negativo, convirtiéndose, por tanto, en una situación de insolvencia. En otras palabras, la causal de disolución por pérdidas patrimoniales es "un mecanismo preconcursal, porque la notoria desproporción entre el capital y el patrimonio puede conducir a la liquidación obligatoria de la sociedad, por causa de imposibilidad para el cumplimiento de las obligaciones sociales." ${ }^{10}$

En cambio, si la sociedad ya es insolvente, se deberá solicitar el inicio del concurso. ${ }^{11}$ En virtud de lo dispuesto en el artículo 9 de la ley 1116 de 2006,

9 Emilio Beltrán Sánchez, La responsabilidad de los administradores por obligaciones sociales, en Ángel Rojo y Emilio Beltrán Sánchez (direc.), La responsabilidad de los administradores de sociedades mercantiles (Valencia: Tirant lo blanc, 2013), p. 256.

10 Francisco Reyes Villamizar, Disolución y Liquidación de Sociedades (Bogotá: Ediciones Doctrina y Ley, 1998), p. 111.

11 José Machado Plazas, Pérdida del capital social y responsabilidad de los administradores 
para poder iniciar un proceso de reorganización o de liquidación judicial, será necesario que el deudor se encuentre o bien en cesación de pagos o en incapacidad de pago inminente. La mencionada disposición define las dos situaciones, a saber:

"El deudor estará en cesación de pagos cuando: Incumpla el pago por más de noventa (90) días de dos (2) o más obligaciones a favor de dos (2) o más acreedores, contraídas en desarrollo de su actividad, o tenga por lo menos dos (2) demandas de ejecución presentadas por dos (2) o más acreedores para el pago de obligaciones. En cualquier caso, el valor acumulado de las obligaciones en cuestión deberá representar no menos del diez por ciento (10\%) del pasivo total a cargo del deudor a la fecha de los estados financieros de la solicitud (...)".

"El deudor estará en situación de incapacidad de pago inminente, cuando acredite la existencia de circunstancias en el respectivo mercado o al interior de su organización o estructura, que afecten o razonablemente puedan afectar en forma grave, el cumplimiento normal de sus obligaciones, con un vencimiento igual o inferior a un año."

De acuerdo con lo anterior, la cesación de pagos implica que el deudor no puede hacer frente a las obligaciones sociales debido a circunstancias tales como que éste se encuentra en una situación de iliquidez (cuando el activo es superior al pasivo), o está frente a un desbalance (el activo es inferior al pasivo), siempre que no sea posible acceder a crédito. ${ }^{12}$

A diferencia de la legislación española, italiana y norteamericana, la colombiana establece de manera concreta y objetiva cuando un deudor se encuentra en situación de cesación de pagos, de manera que resulta mucho más sencillo para los administradores en Colombia, a diferencia de los de los otros tres países, determinar el momento a partir del cual se presenta la mencionada situación.

La legislación española, en cambio, establece que "se encuentra en estado de insolvencia el deudor que no puede cumplir regularmente con sus obligaciones exigibles." 13 De este modo, el deudor evitará estar inmerso en dicha situación cuando cumpla con las obligaciones a su cargo, y lo haga de manera regular. Se ha dicho que el cumplimiento regular de las obligaciones debe ser entendido como un cumplimiento "ajustado y conforme a la regla", ${ }^{14}$ lo cual, acudiendo a la doctrina italiana, implica tener en cuenta los siguientes supuestos: i) el cumplimiento en atención a las condiciones de modo y tiempo de la propia obligación; y ii) que el cumplimiento y el pago no perjudiquen a los acreedores. ${ }^{15}$

por las deudas sociales (Madrid, 1997), p. 32.

12 Judith Morales Barceló, La responsabilidad de los administradores mercantiles en situación de pérdidas y de insolvencia (Valencia: Tirant lo Blanch, 2013), p. 96.

13 Artículo 2.2 de la Ley Concursal española.

14 Emilio Beltrán Sánchez, La regularidad en el cumplimiento de las obligaciones, el estado de insolvencia y la función del concurso de acreedores, en ADCo, num. 11/2007, p. 46.

Tal sería el caso de realizar una satisfacción indiscriminada de ciertas obligaciones dejando 
Bajo la ley norteamericana, existen por lo menos tres maneras de definir la insolvencia. La primera definición consiste en que una compañía es insolvente cuando no pueda pagar sus deudas en el curso normal de sus negocios. En segundo lugar, existe insolvencia cuando el pasivo de la empresa supera el valor razonable de mercado de los activos de la compañía. En tercer y último lugar, algunas cortes de Estados Unidos han adoptado una definición de insolvencia aún más indeterminada, al señalar que una compañía puede ser considerada insolvente si una transacción dada deja a la compañía con un flujo de caja excesivamente reducido para conducir su negocio. ${ }^{16}$

En virtud de lo dispuesto en el artículo 224 del Código de Comercio, los administradores responderán solidariamente frente a los socios y terceros por los perjuicios que se causen cuando, a pesar de encontrarse la sociedad en situación de cesación de pagos, inicien nuevas operaciones sociales o cuando no informen a los socios que la sociedad se encuentra en dicho estado.

Así las cosas, los administradores de sociedades que se encuentren en cesación de pagos deben abstenerse de celebrar nuevos negocios y deben convocar de inmediato a los socios o accionistas para informarles de dicha situación, con el fin de que adopten las medidas que estimen pertinentes.

Por otra parte, la posibilidad que tiene el deudor de poder iniciar un proceso de reorganización por encontrarse en una situación de incapacidad de pago inminente, le permite a éste evitar que el deterioro de su situación patrimonial afecte a sus acreedores. Lo anterior, dado que si bien el deudor aún no se encuentra en una situación de cesación de pagos, éste prevé que en un futuro cercano lo estará. ${ }^{17}$

A diferencia de lo mencionado anteriormente en cuanto a la claridad con que la ley colombiana precisa el concepto de cesación de pagos, la noción de incapacidad de pago inminente, empleada en el artículo 9 de la ley 1116 de 2006, no contiene criterios objetivos a partir de los cuales se pueda concluir que el deudor se encuentra en dicha situación (con excepción, claro está, de que el vencimiento de las obligaciones debe ser igual o inferior a un año). ${ }^{18}$

de lado otras; enajenar elementos primordiales para el desarrollo de la actividad económica del deudor; o la liquidación apresurada o ruinosa de los bienes del deudor. Fernando Cerdá Albero, El presupuesto objetivo del concurso, en RJCat, núm. 4/2004, p. 994.

16 Marshal Huebner \& Hugh McCullough, The Fiduciary Duties of Directors of Troubled U.S. Companies: Emerging Clarity, The International Comparative Legal Guide to Corporate Recovery and Insolvency (ICLG, 2008)

17 Judith Morales Barceló, La responsabilidad de los administradores mercantiles en situación de pérdidas y de insolvencia (Valencia: Tirant lo Blanch, 2013), p. 335

18 La doctrina extranjera, particularmente la española, ha criticado este hecho señalando que contribuye a crear una situación de inseguridad jurídica. Esperanza Gallego Sánchez, El presupuesto objetivo del concurso en la nueva ley concursal, en Práctica de tribunales: revista de derecho procesal civil y mercantil, núm. 5/2004, pp. 22-40. 
La incapacidad de pago inminente le permite al deudor solicitar el inicio de un proceso de reorganización cuando prevea que no podrá cumplir con obligaciones que aún no son exigibles (el vencimiento no puede ser superior a un año). De lo contrario, esto es, si las obligaciones ya fueren exigibles, el deudor se encontraría en una situación de cesación de pagos. ${ }^{19}$

Para que el deudor se encuentre en incapacidad de pago inminente, deberán concurrir otras circunstancias, en el respectivo mercado o al interior de su organización, que permitan inferir que éste no podrá cumplir normalmente sus obligaciones, como podrían ser: la difícil situación económica que se atraviesa ${ }_{i}$ la dificultad para obtener créditos o financiación, la imposibilidad de recuperar o conservar la empresa, entre otros. ${ }^{20}$

En cuanto a la legitimación para iniciar el proceso de reorganización, el artículo 11 de la ley 1116 establece que para el caso de la cesación de pagos, dicho proceso podrá ser iniciado por el deudor, por uno o varios acreedores titulares de acreencias incumplidas o de oficio por la Superintendencia que ejerza supervisión sobre el respectivo deudor o actividad. Respecto de la situación de incapacidad de pago inminente, estarán legitimados para solicitar el proceso de reorganización tanto el deudor como un "número plural de acreedores externos sin vinculación con el deudor o con sus socios".

De acuerdo con lo anterior, el artículo 23 de la Ley 1116 de 2006 establece que durante el trámite del proceso de reorganización queda suspendido de pleno derecho el plazo dentro del cual se pueden adoptar medidas para enervar la causal por pérdidas patrimoniales. Igualmente, en dicha disposición se establece que en el acuerdo de reorganización debe pactarse expresamente como se subsanará dicha causal. Adicionalmente, el artículo 10 de la misma ley ${ }^{21}$ establece, como presupuesto de admisión al proceso de reorganización, que no haya expirado el plazo para enervar las causales de disolución, sin haber adoptado medidas tendientes a subsanarlas.

Pese a que la situación de pérdidas patrimoniales puede indicar en muchos casos una grave crisis económica, es preciso puntualizar que el hecho de que se disminuya el patrimonio neto por debajo de la mitad del capital suscrito, no significa necesariamente que la sociedad se encuentre en la situación de insolvencia, pues aún podría cubrir sus pasivos.

Las pérdidas son el resultado de la diferencia entre los ingresos y los gastos, de manera que la existencia de pérdidas que reduzcan el patrimonio neto por debajo del capital suscrito implica que existe un consumo de activos o un aumento de pasivos, de tal forma que el valor patrimonial de la sociedad se ve

19 Judith Morales Barceló, La responsabilidad de los administradores mercantiles en situación de pérdidas y de insolvencia (Valencia: Tirant lo Blanch, 2013), p. 336

20 Pedro Prendes Carril, El presupuesto objetivo del concurso: la insolvencia, en AJA, núm. 636, 16 septiembre 2004, p. 3

21 Modificado por el artículo 30 de la Ley 1429 de 2010. 
disminuido. ${ }^{22}$ No obstante lo anterior, dicha situación no tiene que coincidir necesariamente con la insolvencia. De otra parte, es posible que una sociedad no pueda hacer frente a sus obligaciones debido a falta de liquidez y a la imposibilidad de acceder al crédito, pero, a pesar de ello, el patrimonio neto sea superior al capital suscrito. También puede suceder que una sociedad se encuentre en una situación de pérdidas patrimoniales, pero tiene la posibilidad de acceder a financiación, por lo que no se encontraría en una situación de insolvencia. ${ }^{23}$

\section{DEBERES DE LOS ADMINISTRADORES EN SITUACIÓN DE PÉRDIDAS PATRIMONIALES}

Según las voces del artículo 458 del Código de Comercio, cuando se verifiquen las pérdidas indicadas en el ordinal 2 del artículo 457 ibídem, los administradores se deberán abstener de iniciar nuevas operaciones y tendrán que convocar inmediatamente a la asamblea general para informarla de dicha situación.

\section{a. Deber de abStenerse De iniciar nUeVas OPERACIONES SOCIALES}

Los administradores serán solidariamente responsables por las operaciones que comiencen una vez se hayan verificado las pérdidas patrimoniales, siempre que dichas operaciones causen algún perjuicio a los accionistas o terceros. ${ }^{24}$ La expresión "cuando se verifiquen", no ha de ser entendida en el sentido de que la responsabilidad de los administradores se determina exclusivamente a partir del momento en que se realizó la comprobación real de las pérdidas, sino que también surge desde el momento en que las pérdidas debieron ser detectadas. ${ }^{25} \mathrm{El}$ que los administradores respondan desde el momento en que conozcan o deban conocer la existencia de las pérdidas, se sustenta, por una parte, en la protección a los terceros acreedores y, por otra, sobre la base del deber de diligencia con que deben actuar los administradores, dado que és-

22 Adolfo Sequeira Martin, Sacristán Bergía, F, Muñoz Garcia, A. La relación entre el concurso y la situación de pérdidas patrimoniales graves como causa disolutoria de la sociedad anónima, en La Ley, núm 6610, de 15 de diciembre de 2006, pp. 1746-1747. Juana Pulgar Ezquerra, El presupuesto objetivo de apertura de concurso de acreedores, AA.VV. R. García Villaverde, A. Alonso Ureba, J. Pulgar Ezquerra (direc.), Derecho Concursal, Estudio Sistemático de la Ley 22/2003 y de la Ley 8/2003, para la reforma concursal, Madrid, 2003, p. 66.

24 Según la Superintendencia de Sociedades, "el estado financiero idóneo para la verificación correspondiente en estos casos, en principio, es el estado financiero básico, clasificado dentro de los de propósito general, y en segunda instancia, el de periodos intermedios en razón de su naturaleza." Superintendencia de Sociedades de Colombia, Oficio 220-30791, de mayo 18 de 1995.

25 Superintendencia de Sociedades de Colombia, Boletín № 44 de marzo de 1978. 
tos deberán monitorear constantemente tanto la situación patrimonial como contable de la sociedad. ${ }^{26}$

En aquellos casos en que los acreedores de la sociedad no logren percibir sus créditos $\mathrm{y}$, por tanto, sufran un daño, podrán interponer una acción de responsabilidad contra los administradores que continuaron con las distintas actividades de la sociedad luego de haberse producido una pérdida grave de capital. ${ }^{27}$

\section{b. Deber De CONVOCATORIA A LA ASAMblea General}

Los administradores no tienen la obligación de que se logre un acuerdo para poner fin a la situación de pérdidas patrimoniales en que se encuentra la sociedad, sino de convocar inmediatamente a la asamblea de accionistas con un orden del día que incluya la propuesta de disolver la sociedad o la de adoptar medidas alternativas para poder resolver la situación. ${ }^{28}$ Para que se cumpla con el deber de convocatoria, será necesario que se observen las distintas formalidades legales y estatutarias para tal efecto. Es preciso aclarar que los administradores deberán convocar a la asamblea tan pronto conozcan o deban conocer la existencia de dichas pérdidas, por lo que no deberán esperar a la elaboración y presentación de los estados financieros anuales. ${ }^{29}$

El deber de los administradores consistirá en convocar a la asamblea con el fin de que los socios constaten la existencia de la situación. Lo anterior, dado que para los socios normalmente resulta ser complicada la verificación de la situación de pérdidas patrimoniales, debido a la dificultad para acceder a la información contable, salvo que éstos ocupen algún cargo de administración en la sociedad o que tengan conocimiento como consecuencia de la información consignada en los estados financieros. ${ }^{30}$

En virtud de lo dispuesto en inciso 2 del artículo 458 del Código de Comercio, el no convocar inmediatamente a la asamblea hará a los administradores

26 "Si por el contrario, estos deberes se demorasen en el tiempo, como serían aquellos supuestos en los que desde el inicio del año se observaran unas pérdidas graves y que por tener que esperar a la formulación de las cuentas anuales, transcurre todo ese año y parte del siguiente, no se cumpliría la finalidad de esa norma". Judith Morales Barceló, La responsabilidad de los administradores mercantiles en situación de pérdidas y de insolvencia (Valencia: Tirant lo Blanch, 2013), p. 344

27 Efraín Hugo Richard, Perspectivas del derecho de insolvencia (Córdoba: Advocatus, 2010), pp. $124-125$ y $163-165$.

28 Judith Morales Barceló, La responsabilidad de los administradores mercantiles en situación de pérdidas y de insolvencia (Valencia: Tirant lo Blanch, 2013), p. 325.

29 Miguel Ruiz Muñoz, Administradores y deudas sociales: derecho de sociedades versus derecho concursal, en DN, núm. 194/2006, p. 14; Machado Plazas, J, Pérdida del capital social y responsabilidad de los administradores por las deudas sociales, Madrid, 1997, p. 208 ;

30 José Machado Plazas, Pérdida del capital social y responsabilidad de los administradores por las deudas sociales, Madrid, 1997, p. 242 y 243 
solidariamente responsables por los perjuicios que causen a los accionistas y a terceros por las operaciones nuevas posteriores a la fecha en que se constaten las pérdidas indicadas. En este sentido es preciso puntualizar que, según lo dispuesto en el numeral 2 artículo 207 del Código de Comercio, pese a que la obligación que se viene tratando compete en principio a los administradores, es función del revisor fiscal dar cuenta oportunamente a la asamblea de las irregularidades que suceden en el funcionamiento de la sociedad, como sería el caso de la situación descrita, de manera que el revisor fiscal también estaría obligado a convocar directamente la asamblea a reunión extraordinaria cuando considere que las circunstancias lo ameriten (numeral 8 del artículo 207 y artículo 182 ibídem) ${ }^{31}$

La asamblea de una sociedad anónima, cuyo patrimonio neto tenga un valor inferior a la mitad del capital suscrito como consecuencia de las pérdidas sufridas, podrá tomar u ordenar las medidas conducentes para restablecer el patrimonio tales como "la venta de bienes sociales valorizados, la reducción de capital suscrito (... ), la emisión de nuevas acciones, etc." De no adaptarse esas u otras medidas, la asamblea deberá declarar disuelta la sociedad para proceder a su liquidación. ${ }^{32}$

Estas medidas se deben llevar a cabo antes de que transcurra el plazo de 18 meses que establece el inciso 2 del artículo 24 de la Ley 1429 de 2010. ${ }^{33}$ Plazo que empezará a contar a partir de la fecha en que el máximo órgano social se haya reunido para estudiar y conocer los estados financieros respectivos. ${ }^{34}$

La asamblea, una vez constituida, deberá adoptar el acuerdo de disolución o la remoción de la causa. Para tal efecto, como ya se mencionó, el máximo órgano social podrá emitir y colocar acciones con lo cual se podrá mejorar tanto la situación patrimonial como la liquidez de la compañía, siempre que el pago de las acciones sea en dinero. A este respecto, se señala que "debe tenerse en cuenta, en todo caso, que la cuantía en que debe aumentarse el capital suscrito para enervar la causal de disolución por pérdidas, es siempre superior a la simple diferencia matemática entre

31 Superintendencia de Sociedades de Colombia, Oficio 220-39240 de junio 11 de 2003

32 Artículo 459 del Código de Comercio.

33 Se debe entender que dicha disposición derogó el inciso 2 del artículo 459 del Código de Comercio el cual establecía un plazo de 6 meses, dado que el inciso 2 del artículo 24 de la Ley 1429 de 2010 estableció de manera general un plazo de 18 meses para llevar a cabo las medidas pertinentes para evitar la disolución de la sociedad. En este sentido: Superintendencia de Sociedades de Colombia, Oficio 220-034887 del 25 de febrero de 2011; Superintendencia de Sociedades de Colombia, Oficio 220-048318 de abril 11 de 2011. Adicionalmente, el artículo 35 de la Ley 1258 de 2008 establece que por la causal de disolución por pérdidas patrimoniales en las sociedades por acciones simplificadas, habrá un plazo de 18 meses para enervar dicha causal.

34 Superintendencia de Sociedades de Colombia, Oficio 220-034887 del 25 de febrero de 2011; Superintendencia de Sociedades de Colombia, Oficio 220-048318 de abril 11 de 2011. En este sentido, el artículo 35 de la Ley 1258 de 2008 establece que en las sociedades por acciones simplificadas habrá un plazo de 18 meses que se contará a partir de que "la asamblea reconozca su acaecimiento" para enervar la causal por pérdidas patrimoniales. 
la cuantía del capital suscrito y el monto del patrimonio neto de la sociedad en el momento de adoptarse la capitalización. Es lógico que al inyectarse recursos a la sociedad por vía de capitalización, se incrementa automáticamente el valor del capital suscrito $y$, por consiguiente, se eleva la relación numérica mínima exigida en la ley entre el cincuenta por ciento de ese rubro y el monto del patrimonio neto." ${ }^{\prime 35}$

Es preciso subrayar que la ley no ha establecido un término fijo para determinar si efectivamente se ha logrado restablecer el patrimonio. Según explica la Superintendencia de Sociedades, el no haber establecido un plazo específico para comprobar la efectividad de las medidas en cuestión, obedece a la intención del legislador de darle un amplio margen de maniobra al máximo órgano social para que adopte las medidas que estime pertinentes, las cuales pueden conllevar o no la ejecución de distintos actos o gestiones que pueden tomar diferentes tiempos; de manera que establecer un plazo específico desconocería la intención del legislador al restringir el campo de acción de la asamblea. ${ }^{36}$

\section{CONSECUENCIAS DEL NO CUMPLIMIENTO POR PARTE DE LOS ADMINISTRADORES DE SUS DEBERES EN LA ETAPA PRECONCURSAL}

El artículo 458 del Código de Comercio establece que los administradores responden solidariamente por las obligaciones adquiridas por la sociedad cuando se verifique la situación de pérdidas patrimoniales y los administradores no cumplan con los deberes que se vienen analizando. De este modo, los acreedores sociales surgidos tras la ocurrencia de la causal de disolución pueden exigir el pago de su crédito no sólo a su deudor -la sociedad-, sino también a cualquiera de los sujetos solidariamente responsables -los administradores.

Es importante determinar cuáles acreedores están legitimados para ejercer una acción contra los administradores con base en lo dispuesto en el artículo 458 del Código de Comercio. Para dicho propósito, se debe distinguir el momento en que se celebra el acto o el negocio, toda vez que los administradores únicamente serán responsables de aquellas obligaciones que hayan nacido con posterioridad al acaecimiento de la causal de disolución por pérdidas patrimoniales. ${ }^{37}$

35 Francisco Reyes Villamizar, Derecho Societario, Tomo II (Bogotá: Editorial Temis, 2002), pp. 292 y 293.

36 Superintendencia de Sociedades de Colombia, Oficio 220-30791 de mayo 18 de 1995.

37 Tanto la doctrina como la jurisprudencia española añaden al hecho de que la obligación haya surgido con posterioridad al acaecimiento de la causal de disolución que se viene tratando, que el acreedor desconozca la situación de pérdidas patrimoniales en que se encontraba la sociedad. Lo anterior, dado que la jurisprudencia española ha admitido que el conocimiento por parte del acreedor de la situación de la sociedad es causa de exoneración de responsabilidad. En este sentido: Ignacio Sancho Gargallo, La responsabilidad de los administradores por las deudas de la sociedad, derivada del incumplimiento de los 
Así las cosas, el momento fundamental para determinar el alcance de la responsabilidad de los administradores por pérdidas patrimoniales, será el del nacimiento de las obligaciones. Por lo que no estarán legitimados aquellos acreedores titulares de créditos que se hayan originado con anterioridad a la ocurrencia de la causal de disolución, con independencia que su vencimiento sea posterior al acaecimiento de dicha causal, toda vez que el acreedor debe asumir el riesgo de la evolución de la sociedad deudora de su crédito. ${ }^{38}$

El cumplimiento tardío del deber de convocar a la asamblea como consecuencia de la situación de pérdidas patrimoniales no produce efectos respecto de los acreedores que ya tenían derecho a reclamar a la sociedad, sino sólo respecto de las deudas sociales que hayan sido adquiridas con posterioridad. Tan pronto se cumpla el deber de convocar a la asamblea, los administradores dejan de responder por las nuevas obligaciones que adquiera la sociedad, pero continúan respondiendo de aquellas por las que ya fueran responsables. ${ }^{39}$

En el entendido de que los deberes de los administradores frente a una situación de pérdidas patrimoniales consisten en atender unos requisitos formales, cabe preguntarse si los administradores siguen siendo responsables cuando cumplan con sus deberes, pero lo hagan por fuera de los plazos establecidos en la ley. Si bien la ley establece plazos sin contemplar excepciones, no es menos cierto que cuando los administradores den cumplimiento a sus deberes legales, dejaría de tener sentido que sigan respondiendo por las obligaciones sociales posteriores a ese cumplimiento, puesto que la finalidad de esos deberes es que los socios tengan conocimiento de la situación que atraviesa la sociedad. Por tanto, los administradores deberían responder por las obligaciones sociales posteriores al acaecimiento de la causal de disolución, pero anteriores a que se dé cumplimiento a los deberes legales. ${ }^{40}$

De otra parte, en cuanto al ámbito subjetivo de la sanción, tanto la jurisprudencia como la doctrina española establecen algunos criterios que consideramos plenamente aplicables en Colombia, dentro de los que destacamos los

deberes legales de promover la disolución (artículos 262 TRLSA y 105 LSRL)", en AA.VV., R. Gimeno-Bayón Cobos y L. Garrido Espá (direc.), Órganos de la sociedad capital, Valencia, 2008, Tomo I, pp. 1010 y 1011.

38 Margarita Viñuedas Sanz, La modificación del ámbito objetivo de la responsabilidad de los administradores por las deudas sociales, en RDM, núm. 266/2007, p. 1013.

39 Emilio Beltrán Sánchez, La responsabilidad de los administradores por obligaciones sociales, en Ángel Rojo y Emilio Beltran (direc.), La responsabilidad de los administradores de sociedades mercantiles, (Valencia: Tirant lo blanc, 2013), p. 273.

40 Emilio Beltrán Sánchez, La responsabilidad de los administradores por obligaciones sociales, en AA. VV., E.M. Beltrán Sánchez y A. J. Rojo Fernández-Río (coord.), La responsabilidad de los administradores, Valencia, 2011, pp. 293 y 297; José Carlos González Vázquez, Disposición final vigésima. Reforma de la Ley de Sociedades Anónimas, AA.VV., J. Sánchez Calero y V.A. Guiarte Gutiérrez (direc.), Comentarios a la Legislación Concursal, Valladolid, 2004, p. 2857. 
siguientes: la sanción se impone a los administradores de la sociedad, es decir, a quien actúe como tal el día del vencimiento del plazo para el cumplimiento de sus deberes; la sanción se aplica también a los denominados administradores de hecho, toda vez que se les deben hacer extensivas las normas relativas a la responsabilidad de los administradores de derecho (no sería razonable que disfrutase de mejores condiciones el administrador de hecho que el de derecho); la cesación en el cargo de administrador con anterioridad al plazo fijado en la ley para cumplir los deberes, lo libera de responsabilidad, salvo que siga actuando como administrador de hecho. ${ }^{41}$

\section{CONCLUSIONES}

En suma, ante el incumplimiento del deber de convocar inmediatamente a la asamblea general cuando se haya verificado -o se haya debido verificar- el acaecimiento de la causal de disolución por pérdidas patrimoniales, vale decir, que las pérdidas hayan reducido el patrimonio neto a una cantidad inferior a la mitad del capital suscrito, o se hayan adelantado operaciones posteriores a esa situación, los administradores serán solidariamente responsables de las deudas sociales, posteriores al momento en que acaeció dicha causal de disolución.

\section{BIBLIOGRAFÍA}

Emilio Beltrán Sánchez, La responsabilidad de los administradores por obligaciones sociales, en Ángel Rojo y Emilio Beltrán (direc.), La responsabilidad de los administradores de sociedades mercantiles, Valencia: Tirant lo blanc, 2013.

Emilio Beltrán Sánchez, La regularidad en el cumplimiento de las obligaciones, el estado de insolvencia y la función del concurso de acreedores, en ADCo, num. 11/2007.

Fernando Cerdá Albero, El presupuesto objetivo del concurso, en RJCat, núm. 4/2004.

Esperanza Gallego Sánchez, El presupuesto objetivo del concurso en la nueva ley concursal, en Práctica de tribunales: revista de derecho procesal civil y mercantil, núm. 5/2004.

José Carlos González Vázquez, Disposición final vigésima. Reforma de la Ley de Sociedades Anónimas, AA.VV., Juan Sánchez-Calero y Vicente Guilarte Gutiérrez (direc.), Comentarios a la Legislación Concursal, Valladolid: Lex Nova, 2004. 
Marshal Huebner \& Hugh McCullough, The Fiduciary Duties of Directors of Troubled U.S. Companies: Emerging Clarity, The International Comparative Legal Guide to Corporate Recovery and Insolvency (ICLG, 2008).

José Machado Plazas, Pérdida del capital social y responsabilidad de los administradores por las deudas sociales, Madrid, 1997.

Fernando Marín de la Bárcena Garcimartín, Responsabilidad por deudas y derecho de daños, en RdS, núm. 31/2008

Judith Morales Barceló, La responsabilidad de los administradores mercantiles en situación de pérdidas y de insolvencia, Tirant lo Blanch, Valencia, 2013, p. 319

Pedro Prendes Carril, El presupuesto objetivo del concurso: la insolvencia, en AJA, núm. 636, 16 septiembre 2004.

Juana Pulgar Ezquerra, El presupuesto objetivo de apertura de concurso de acreedores, AA.VV. R. García Villaverde, A. Alonso Ureba, J. Pulgar Ezquerra (direc.), Derecho Concursal, Estudio Sistemático de la Ley 22/2003 y de la Ley 8/2003, para la reforma concursal, Madrid, 2003.

Jesús Quijano González, Responsabilidad de los administradores por no disolución de la sociedad, en Rds, núm. 5/1995.

Efraín Hugo Richard, Perspectivas del derecho de insolvencia, Advocatus, Córdoba, 2010

Francisco Reyes Villamizar, Derecho Societario, Tomo II, Bogotá: Editorial Temis, 2002.

Francisco Reyes Villamizar, Disolución y Liquidación de Sociedades, Bogotá: Ediciones Doctrina y Ley, 1998.

Miguel Ruiz Muñoz, Administradores y deudas sociales: derecho de sociedades versus derecho concursal, en DN, núm. 194/2006, p. 14;

Ignacio Sancho Gargallo, La responsabilidad de los administradores por las deudas de la sociedad, derivada del incumplimiento de los deberes legales de promover la disolución (artículos 262 TRLSA y 105 LSRL)", en AA.VV., R. Gimeno-Bayón Cobos y L. Garrido Espá (direc.), Órganos de la sociedad capital, Valencia, 2008, Tomo I.

Adolfo Sequeira Martin, La relación entre concurso y la situación de pérdidas patrimoniales graves como causa disolutoria en la sociedad anónima, en La Ley, núm. 6610, de 15 de diciembre de 2006.

Superintendencia de Sociedades de Colombia, Boletín N 44 de marzo de 1978. 
Superintendencia de Sociedades de Colombia, Oficio 220-30791, de mayo 18 de 1995.

Superintendencia de Sociedades de Colombia, Oficio 220-4880 de septiembre 25 de 2002.

Superintendencia de Sociedades de Colombia, Oficio 220-39240 de junio 11 de 2003.

Superintendencia de Sociedades de Colombia, Oficio 220-034887 del 25 de febrero de 2011;

Superintendencia de Sociedades de Colombia, Oficio 220-048318 de abril 11 de 2011.

Margarita Viñuedas Sanz, La modificación del ámbito objetivo de la responsabilidad de los administradores por las deudas sociales, en RDM, núm. 266/2007, p. 1013. 